\title{
CLINICAL EVALUATION OF THE EFFECT OF STANDARD AND MODIFIED STANDARD FLAPS DESIGN IN THE REMOVAL OF MESIO-ANGULAR IMPACTED LOWER $3^{\text {RD }}$ MOLAR
}

\author{
Mahmoud Hasan ALawur* and Reda Noval**
}

\begin{abstract}
Aim of the study: The propose of this study was designed to establish a successful comparison between removal of impacted lower third molar (wisdom tooth) using two different flap designs (standard and modified standard flap) in post-operative pain, trismus and swelling,

Methodology: The comparison was done after the removal of the impacted teeth using a specific criteria that was numbered and described in a this research, a total of ten systemically free patient with mesio-angular impacted lower third molar was choose as a candidate for conducting this research, the patients was divided into two groups (group 1 and group 2), a standard flap was used with the first group, in standard flap the vertical releasing incision was started at the level of buccal groove of the seven, while in group 2 a modified standard flap was used, in modified standard flap the vertical releasing incision was started just distally to the first molar .
\end{abstract}

Conclusion: finally, we concluded at the end of this study that the choice between these two flaps in removal of impacted lower third molar have no significant difference when compared to post-operative pain, swelling and trismus.

KEYWORDS: Impaction, Flaps, wisdom tooth, lower third molar

\section{INTRODUCTION}

The tooth becomes impacted because adjacent teeth, dense overlying bone, excessive soft tissue, or a genetic abnormality prevents eruption. Because impacted teeth do not erupt, they are retained for the patient's lifetime unless surgically removed or exposed because of resorption of over lying tis- sues the term un-erupted referred to the teeth which failed to erupt into oral cavity or teeth in the process of eruption. Teeth most often become impacted because of inadequate dental arch length and space in which to erupt; that is, the total length of the alveolar bone arch is smaller than the total length of the tooth arch (Karl R. Koerner. 2004). The most common impacted teeth are the maxillary and mandibu-

* Dental Intern at UMM AlQura University Faculty of Dentistry

** Associated Professor of Oral and Maxillofacial Surgery 
lar third molars, followed by the maxillary canines and mandibular premolars. The third molars are the most frequently impacted because they are the last teeth to erupt; therefore, they are the most likely to have inadequate space for eruption.

As a general rule, all impacted teeth should be removed unless removal is contraindicated theses contra indication may include:

1. Damaging to the adjacent vital structure during surgical removal

2. Age of the patient as the bone become more calcified so procedure is moretraumatic 3)medically compromised patient.

\section{Classification systems of impacted teeth:}

With careful classification of the impacted teeth using a variety of systems, the surgeon can approach the proposed surgery in an orderly fashion and predict whether any extra ordinary surgical approaches will be necessary or if the patient will encounter certain postoperative problems. The majority of classification schemes are based on analysis of a radiograph. The panoramic radiograph shows the most accurate picture of the total anatomy of the region and is the radiograph of choice for planning removal of impacted third molar and the assessment should include: 1) angulation 2) relation to the ramus 3)relationship to occlusalplane. (Jmes R Hub et al., 2008

\section{Literature Review}

Over the years, different surgeons suggested different types of flap design that can be used for the removal of impacted lower third molar(Peterson LJ 1993) while only few studies have been carried out to compare the effect of choosing a certain flap design over another on post-operative complaints(Wadhwani KK et al., 2004).

The presence of various important anatomical structures in the adjacent area around the surgical site has made many surgeons to design an incision, ranging from envelope (Koener's) incision, triangular (Ward's) incision, and its' modification, L shaped incision, bayonet shaped incision, comma incision, and "S" shaped incision(BaqainZH et al.,2012).

In Muscat finding of a study showed in radiographic investigation the prevalence of third molar impactionthe high prevalence found, with more than half of the study population having at least one impacted third molar, underlines the need to increase awareness among dental professionals. Further studies should also be conducted to determine how many patients with impacted third molars are symptomatic or actively seek treatment. Further studies are also needed to assess the pattern of third molar. A study In Muscat showed in radiographic investigation the prevalence of third molar impaction the high prevalence found, with more than half of the study population having at least one impacted third molar, underlines the need to increase awareness among dental professionals. Further studies should also be conducted to determine how many patients with impacted third molars are symptomatic or actively seek treatment. Further studies are also needed to assess the pattern of third molar impaction in other regions.

According to Elsey and Rock; the incidence of third molar impaction is up to $73 \%$ of young adults in Europe. Generally, third molars have been found to erupt between the ages of 17 and 21 years. The incidence of third molar impaction is increasing in the modern generation due to insufficient space in maxillary and mandibular arches and that's may be a result of evolution. Another study was done in Assir in Kingdome of Saudi Arabia found that the prevalence of impacted tooth is more in mandible than maxilla, and prevalence of impacted tooth was found to more in females than in males, and a mesio-angular impaction was found the most prominent type of impacted third molar (Bokhari K et al), while in Jeddah found that prevalence of third 
molar impaction was the highest compared to upper canine, lower premolar and other teeth. (Khalid H. Zawawi. 2012.).

Faubion found that extraction of premolar before the time of third molar tooth decrease but not eliminate the impaction of third molar, while Richardson found in his study that the extraction of permeant molar eliminate the incidence of third molar impaction completely (Margret E. et.al july 1977) .

Pain associated with impacted third molar along with swelling and trismus (as a result of inflamed muscles) are usually persist with the patient to several days and it may differed from different individuals as a result of a different response from each patient the the surgical insult along with other variables (e.g operation time) (Coulthard. P. et al. 2014). And incidence of alveolar osteitis (dry socket) has a reported incidence of $1 \%$ (Goldberg 1985) to $2.9 \%$ (Muhonen 1997). A reduction in dry socket and reduction in pain was reduced in triangular flap design in comparison with envelop flap design as reported by Coulthard P (Coulthard $P$ et.al 2014). In India a comparative study between removal of impacted teeth using chisels and using a rotary surgical burs found that there is no significant difference between the two techniques in respective of post-operative swelling and bleeding, and postoperative pain was found to be greater in manual removal of impacted teeth (Singh, et al. 2017). In the present generation, the incidence of impacted teeth was found to be increases

\section{AIM OF THE STUDY}

The aim of this is to determine the postoperative effect of the removal of impacted lower $3^{\text {rd }}$ molar by using of 2 different flap design in comparison of postoperativepain, swelling and truisms.

The following null hypothesis has been tested: There are no difference between standard and modified standard flap design in comparison between postoperative pain, swelling and trismus.

\section{PATIENTS AND METHODS}

A clinical trail study of 10 patients with impacted mesio-angular lower $3^{\text {rd }}$ molar was conducted in UMM AL-Qura dental teaching hospital in Makkah city. The sample was taken from the screening in the same hospital a 10 patient was taken from the age of 25 years to the age of 35 years old with no systemic conditions that will affect the result of the study. Assessment of the position, class and depth of the impacted teeth was done by using the patient panoramic x-ray. A visual analogue pain examination was used to measure the postoperative pain, the trismus will be measured by measurement of the maximum mouth opening before and after the surgery is done and the swelling was measured by visual criteria with deferent grades, the patients was divided into 2 groups, the standard flap was used with group 1 , while the modified standard flap used used with group $\underline{2}$. The standard flap design which was used in removal of the impacted tooth in group 1: include an anterior incision curves forwards from the disto-buccal corner of the crown of the second molar and ends alongside the mesio-buccal cusp of the same second molar (figure 1). The modified standard flap design which was used in removal of the impacted tooth in group 2: the anterior vertical incision is commenced at the disto-buccal corner of the crown of the lower first molar and extended forwards alongside that tooth. A horizontal incision is made in the buccal gingival crevice of the second molar and then the incision is extended along the buccal side of the tooth to the external oblique ridge (figure 2). The pre-operative evaluation for each participant will include panoramic $\mathrm{x}$-ray, periapical $\mathrm{x}$-ray and photographs. The impacted tooth with the first group will be removed by using standard flap which is a mucoperiosteal flap developed through a horizontal incision along free gingival margin with vertical releasing incision posterior to the second molar. While the second group the impacted tooth will be removed by using a modified standard flap which is a Mucoperiosteal flap developed through a horizontal incision along free gingival margin with 
vertical releasing incision anterior to the second molar. The assessment of Post-operative Pain will be as the following: The pain was evaluated subjectively according to the following criteria: $0=$ No pain., $1=$ Mild pain: It is easily tolerated. $2=$ Moderate pain: It is causing discomfort, but bearable. $3=$ Severe pain: It is causing discomfort, hardly tolerated and unbearable. The Assessment of Postoperative Swelling will be as the following: The postoperative swelling was assessed subjectively by criteria developed by Sabur (3) as follows: Grade $0=$ No swelling.

Grade $1=$ edema that involves the alveolar mucosa buccally and/or lingually (intraorally).

Grade $2=$ edema that involves the alveolar mucosa buccally and/or lingually, and involves the cheek (extra orally) to the lower border of the mandible.

Grade $3=$ edema that involves the alveolar mucosa buccally and/or lingually, and involves the cheek (extra orally) below the lower border of the mandible.

The maximum mouth opening ability measured in millimeters was recorded between right upper and right lower central incisors with the use of calibrated sliding caliper. Mouth opening was recorded preoperatively, 1 day, 3 days and again on 7 days' postoperatively.

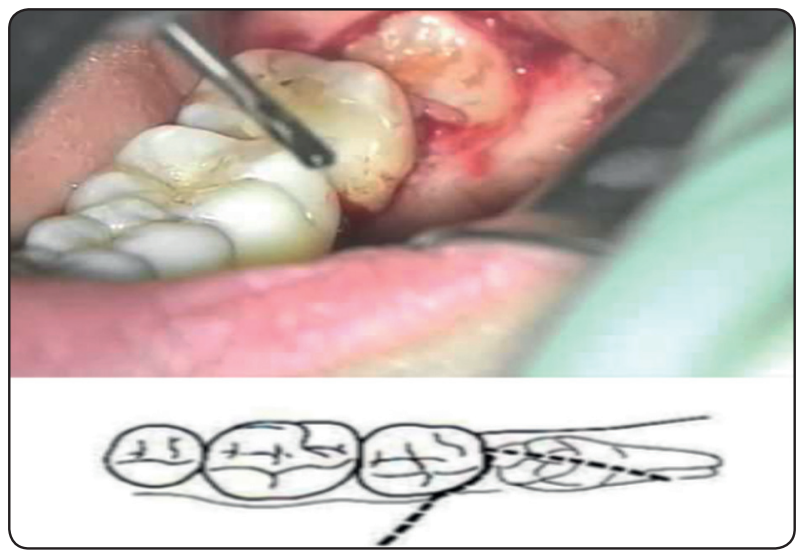

Fig. (1) Standard flap
Percentage of trismus was calculated according to the following equation: Post-operative mouth opening $(\mathrm{mm}) \backslash$ Pre-operative mouth opening $(\mathrm{mm}) * 100$. The assessment of post-operative pain, swelling and trismus had been documented in a measurement paper as mentioned previously (figure 3).

\section{Surgical procedure}

The armamentarium used in the surgical procedure include: Lagenback and Minnesota retractors for the retraction of the cheek and tongue. Periosteal elevator used in two sizes to control the flap after reflection. Blade \#15 for the incision of the tissues (figure 1). Surgical fissure bure used for the sectioning of the impacted tooth, buccal applicator used for the luxation and delivery of the tooth (figure 2), and sterile synthetic absorbable braided polyglycolic acid suture (figure 3 ). All of the operations were performed under local anesthesia which was obtained by inferior alveolar nerve block, lingual nerve block and long buccal nerve block using 1.7 articaine hydrochloride $4 \%$ with 1/100000 epinephrine (figure 5). A standard surgical technique was used for all patients as described by Killey Following reflection of mucoperiostealflap and bone removal was done as needed.

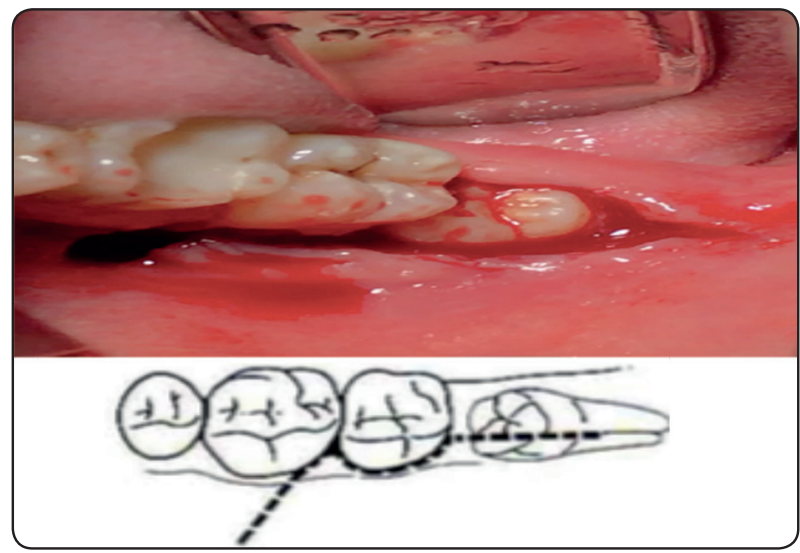

Fig. (2) Modified standard flap 
After removal of the impacted teeth in all patient the socket was irrigated with normal saline $10 \mathrm{ml}$, and suture was done to close the incision.

All patient was described an antibiotic medication amoxicillin $500 \mathrm{mg}$ orally 3 times a day for 4 days and paracetamol tablets as pain killer 500 mg 4 times a day for 5 days' post-operatively.

Group 1 pain assessment: At the first post-operative interval for group 1 pain assessment: 1 patient showed grade 1, 3 patients showed grade 2 and 1 patient showed grade 3 pain. At 3days post-operative interval: 4 patients reported grade $1(80 \%)$ and only 1 patient reported grade 2 (20\%).At 7 days post-operative interval: all the subject reported pain grade 1. Group 2 pain assessment: At the first post-operative day: 3 patients reported grade1(60\%), 1 patient with grade $2(20 \%)$ and 1 patient grade $3(20 \%)$. At 3 days, postoperative interval: 1 patient reported grade $0(20 \%), 2$ patients with grade $1(40 \%)$ and 2 patients with grad 2 (40\%). (table 1).

TABLE (1) Post-operative pain assessment results

\begin{tabular}{|c|c|c|}
\hline Pain & Group 1 & Group 2 \\
\hline \multirow[t]{3}{*}{ After 1 day } & 1 patient $=$ grade 1 & 3 patient $=$ grade 1 \\
\hline & 3 patient $=$ grade 2 & 1 patient $=$ grade 2 \\
\hline & 1 patient $=$ grade 3 & 1 patient $=$ grade 3 \\
\hline \multirow[t]{3}{*}{ After 3 days } & 4 patient $=$ grade 1 & 1 patient $=$ grade 0 \\
\hline & 1 patient $=$ grade 2 & 2 patient $=$ grade 1 \\
\hline & & 2 patient $=$ grade 2 \\
\hline \multirow[t]{2}{*}{ After 7 days } & \multirow{2}{*}{$\begin{array}{l}\text { All of the patient } \\
\text { experienced } \\
\text { grade } 1 \text { pain }\end{array}$} & 4 patient $=$ grade 0 \\
\hline & & 1 patient $=$ grade 1 \\
\hline
\end{tabular}

\section{Post-operative swelling assessment}

Group 1: At the first post-operative day: 3 patients showed grade $3(60 \%)$, and 2 patients showed grade $2(40 \%)$.
TABLE (2) Post-operative swelling assessment results

\begin{tabular}{|c|c|c|}
\hline Swelling & Group 1 & Group 2 \\
\hline \multirow[t]{3}{*}{ After 1 day } & 3 patient $=$ grade 3 & 1 patient $=$ grade 1 \\
\hline & 2 patient $=$ grade 2 & 3 patient $=$ grade 2 \\
\hline & & 1 patient $=$ grade 3 \\
\hline \multirow[t]{2}{*}{ After 3 days } & 1 patient $=$ grade 1 & 2 patient $=$ grade 1 \\
\hline & 4 patient $=$ grade 2 & 3 patient $=$ grade 2 \\
\hline \multirow[t]{2}{*}{ After 7 days } & 3 patient $=$ grade 1 & 4 patient $=$ grade 0 \\
\hline & 2 patient $=$ grade 0 & 1 patient $=$ grade 1 \\
\hline
\end{tabular}

\section{Post-operative mouth opening assessment:}

The preoperative mouth opening of the all subjects in the first group was in total equalto $245 \mathrm{~mm}$ ( $48 \mathrm{~mm}+50 \mathrm{~mm}+51 \mathrm{~mm}+47 \mathrm{~mm}+49 \mathrm{~m} \mathrm{~m}=$ $245 \mathrm{~mm}$ ). While in group 2 the mean value of the mouth opening in all subjects was $248 \mathrm{~mm}$ $(50 \mathrm{~mm}+52 \mathrm{~mm}+47 \mathrm{~mm}+50 \mathrm{~mm}+49 \mathrm{~mm}=248 \mathrm{~mm})$ At the first post-operative day:The post-operative maximum mouth opening of the subjects in group 1 was $=184 \mathrm{~mm}$ at the first post-operative day $(36 \mathrm{~mm}+37 \mathrm{~mm}+38 \mathrm{~mm}+35 \mathrm{~mm}+38 \mathrm{~mm})$, and by applying the equation mentioned above the postoperative moth opening mean value was $=75.10 \%$ $(48 \mathrm{~mm}+50 \mathrm{~mm}+51 \mathrm{~mm}+47 \mathrm{~mm}+49 \mathrm{~mm} \backslash 36 \mathrm{~mm}+37 \mathrm{~m}$ $m+38 m m+35 m m+38 m m=184 \backslash 245 * 100=75.10 \%)$, while in group 2 the mean value of maximum mouth opening was $=187 \mathrm{~mm}$ so the mouth mean was $=81.45$ $\%(50+52+47+50+49 \backslash 40+43+39+41+39=187 \backslash 248=$ $81.45 \%)$. Group 2 showed a higher mean of trismus than group 1, however no significant difference between the 2 groups at the first day interval. At 3 days, post-operative interval: Group 1 showed mean value $=78.36 \%$, while group 2 subjects showed mouth opening mean value $=84.24 \%$, although group 2 showed a higher mean value than group 1 no significant difference appeared. At 7 days, postoperative interval: Subjects of group 1 showed a mean value of maximum moth opening $=95.10 \%$, 
and group 2 showed a mean value of $93.95 \%$, although no significant difference appear between the two groups in maximum mouth opening. (table 3).

TABLE (3) Post-operative assessment of maximum mouth opening (trismus)

\begin{tabular}{|c|c|c|}
\hline Swelling & Group 1 & Group 2 \\
\hline After 1 day & Mean $=75.10 \%$ & Mean $=81.45 \%$ \\
\hline After 3 days & Mean $=78.36 \%$ & Mean $=84.24 \%$ \\
\hline After 7 days & Mean $=95.10 \%$ & Mean $=93.95 \%$ \\
\hline
\end{tabular}

\section{DISCUSSION}

The two main factors that may contribute to postoperative complication when removing an impacted tooth was removal of excess amount of bone and soft tissue handling and incision design (Koerner KR 1993). According to the literature review that was done in this research there are a few research that correlate between the effect of the incision design and the post-surgical complain from the patient Pain and swelling along with limitation of mouth opening are the most common complaint from the patients after the removal of their impacted teeth, and this study we compare two different flap design in the aspect of the post-surgical pain, swelling and trismus since it's the most common complains as mentioned before.

The statistical comparison in postsurgical pain was appeared as non-significant in between standard and modified standard flap between the two study groups, and this finding was coincide with finding of Braccoet al., who stated that the post-surgical pain is not relate to the type of reflected, and instead the pain is related to releasing of but due to the release of endogenous mediators such as bradykinin, serotonin and raising in tissue tension within the inflamed area is another cause of post-surgical pain. (Koerner KR 1993).
In statistical comparison in 1day, 3days and 7 days interval our findings in this research shows no significant difference between the two flaps preformed in this study, and this finding may be because the post-surgical swelling is a result of accumulation of fluid in the interstitial tissues (Forsgren H.; 1985), and the cause of post-surgical swelling may be contributed to injury of periosteum during the reflection or incision of the flap (Sabur JJ;.1993) .

\section{CONCLUSION}

The choice between the standard and modified standard flap seems to have no effect in post-surgical complains, in regarding to pain, swelling and trismus in the 1day, 3days and 7 days interval and further investigation is recommended to determine the effect of the flap design for longer post-surgical period.

\section{REFERENCES}

1. AL-Anqudi SM, AL-sudairy S, AL-husani A, AL-muniri A. prevalence and pattern of third molar impaction.Sultan Taboos University Med, August 2014 Vol, 14. Iss. 3, pp. e388-392, Epub. 24th jul 14

2. Baqain ZH, Al-Sha I A, Hamdan AA, Sawair FA. Flap design and mandibular third molar surgery: A split mouth randomized clinical study. Int J Oral MaxillofacSurg 2012;41:1020-4.

3. James R. HUPP, EdwardEllis III, Mayron R. Tucker Principles Of Management Of Impacted Teeth, contemporary Oral And Maxillofacial surgery P.149.

4. Peterson LJ. Contemporary Oral and Maxillofacial Surgery. 2nd ed. CV Mo- sby Co, St Louis. 1993; Pp: 225-260.

5. Wadhwani KK, Garg A. Healing of soft tissue after different types of flap designs used in periapical surgery. Endodontol. 2004; 16: 19-22.

6. Coulthard P, Bailey E, Esposito M, Furness S, Renton TF, Worthington HV. Surgical techniques for the removal of mandibular wisdom teeth. Cochrane Database of Systematic Reviews 2014, Issue 7. Art. No.: CD004345.DOI: 10.1002/14651858.CD004345.pub2. 
7. Faubion, B. H .: effect of extraction of premolars in eruption of mandibular third molars. J. Amer. Dent. Ass. 76: $316,1968$.

8. Richardson, M. E.: the early developmental position in the lower third molar relative to certain jaws dimensions. Angle orthodont. 40:226, 1970.

9. Khan NB, Chohan AN, AlMograbi B, AlDeyab S, Zahid T, AlMoutairi M. Eruption Time of Permanent First Molars and Incisors Among a Sample of Saudi Male Schoolchildren. Saudi Dent J. 2006 Jan-Apr;18(1):18-24.

10. Elsey MJ, Rock WP. In uence of orthodontic treatment on development of third molars. Br J Oral Maxillofac Surg. 2000 Aug;38(4):350-3.

11. MaungMaungLatt, PruedyChewpreecha, NatthametWongsirichatprediction of difficulty in impacted lower third molare extraction; review literatureVolume 35 Number 3 September-December 2015.

12. Divya.T et al/J. Pharm. Sci. \& Res. Vol. 6(11), 2014, 363367

13. REGEZIJA, KERRDA, COURTNEXRM. Odontogenic tumors: analysis of 706 cases. J Oral Surg 1978: 36:771 8.

14. WEIR JC, DAVENPORT WD, SKINNER RL. Diagnostic and epidelniologicsur- vey of 15,783 oral lesions. JADA 1987: 115: 439-42.

15. SHEARM, SINGHS. Age-standardized incidence rates of ameloblastoma and dentigerous cyst $n$ the Witwatersrand Dent Oral Epid 1978: 6: 195

16. Pahkala R, Pahkala A, Laine T. Eruption pattern of permanent teeth in a rural community in northeastern Finland. ActaOdontol Scand. 1991 Dec;49(6): 341 [Medline: 1776401] [doi: 10.3109/00016359109005930]
17. M Dent J Volume 35 Number 3 September-December 2015

18. Coulthard P, Bailey E, Esposito M, Furness S, Renton TF, Worthington HV 2013

19. Killey HG, Seward GR, Kay LW. An Outline of Oral Surgery. Part One. Revised Reprint. John Wright and Sons, Ltd. Bristol. 1975; Pp: 25-54.

20. Koerner KR. Basic procedures in oral surgery. Dent Clin North Am. 1994; 38(2): 255-271.

21. BraccoP,Debernardi C, Coscia D, Pasqualini D, Pasqualicchi O, Calabre-se N. Efficacy of rofecoxib and nimes-ulide in controlling post- operative pain in oral surgery: A randomized co-mparative study. Curr Med Res Opin. 2004; 20(1): 107-112.

22. Forsgren H, Heimdahl A, Johansson B, Krekmanov L. Effect of application of cold dressings on post-operative course in oral surgery. Int J Oral Surg. 1985; 14: 223-228.

23. Sabur JJ. Clinical evaluation of the dexamethasone and piroxicam for the control of swelling, trismus and pain following the removal of impacted lo- wer third molar. MSc thesis. College of Dentistry. University of Baghdad. 1993.

24. Van der Westhuijzen AJ, Roelofse JA, Becker PJ. Randomized double blind comparison of tiaprofenic acid and diclophenac sodium after third molar surgery. Oral Surg Oral Med Oral Pa- thol. 1994, 78(5): 557-566.

25. The findings of this study regarding to trismus found that there is no significant diffrance between the two groups in trismus at 1,3 and 7 days interval, although the highest degree of trismus was found to be in the first post-surgical day interval and this may be due to the excessive pain in this period as suggested by Van der $40 \%$ 